Research Paper:

\title{
Relationship Between Physiological Factors, Emotional Status and Daily Activities With Sleep Quality in Spinal Cord Injury
}

Nasim Joudi ${ }^{1}$ (D), *Mehdi Alizadeh Zarei ${ }^{1}$ (D), Malahat Akbarfhimi ${ }^{1}$ (i)

1. Department of Occupational Therapy, School of Rehabilitation Sciences, Iran University of Medical Sciences, Tehran, Iran

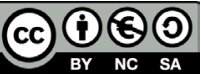

*This work has been published under CC BY-NC-SA 4.0 license.

Article info:

Received: 25 Feb 2021

Accepted: 24 May 2021

Available Online: 07 Aug 2021

\section{Funding}

This study was supported by the Iran Universality of Medical Sciences.

\section{Conflict of interest}

The authors declared no conflict of interest.

\section{ABSTRACT}

Background and Objectives: Generally, spinal cord injuries can lead to functional limitations and restrict participation in different areas of occupations. One of the areas of occupations that are less considered is rest and sleep. The aim of this study was to investigate the relationships between physiological, emotional status and daily activities, and sleep quality in patients with spinal cord injury.

Methods: The present study was a cross-sectional analytical study that was conducted in 20192020. The statistical population of this study was patients with spinal cord injury referring to the occupational therapy clinics in Tehran and Karaj as well as hospitalized patients and daily patients referring to the Kahrizak care unit in Alborz province. The sample size was considered 100 spinal cord injury patients who were randomly selected. Data were collected using Pittsburgh Sleep Quality Questionnaire, STOP-BANG Respiratory Apnea Probability Questionnaire, Beck Anxiety and Depression Questionnaire, Pain Scale, and Barthel Questionnaire.

Results: The results showed that there was a significant relationship between the risk factors of respiratory apnea, anxiety, depression, pain, the time elapsed after the accident and functional mobility, and sleep quality $(\mathrm{P} \leq 0.05)$.

Conclusion: Sleep quality in patients with spinal cord injury is low and is significantly associated with factors, such as the likelihood of respiratory apnea, pain, mood factors anxiety and depression, muscle tone, functional mobility, and independence in daily activities

Keywords: Spinal cord injury, Sleep hygiene, Apnea, Depression, Anxiety

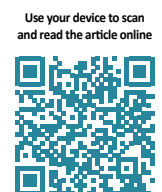

Cite this article as Joudi N, Alizadeh Zarei M, Akbarfhimi M. Relationship Between Physiological Factors, Emotional Status and Daily Activities With Sleep Quality in Spinal Cord Injury. Function and Disability Journal. 2021; 4:E30. http://dx.doi. org $/ 10.32598 /$ fdj. 4.30

Address: Department of Occupational Therapy, School of Rehabilitation Sciences, Iran University of Medical Sciences, Tehran, Iran. Tel: +98 (912) 3070065

E-mail:m.alizadeh@yahoo.com 
† What is "already known" in this topic:

Patient with spinal cord injury involved with poor quality of sleep and some factors such as respiratory problems, mood disorders can affect on it.

$\rightarrow$ What this article adds:

Quality of sleep has significant relationship with physiological, emotional factors and activities of daily living.

\section{Introduction}

$\mathrm{T}$

he spine is the main part of human ossification in the upper torso, divided into cervical, thoracic, lumbar, sacral, and coccyx parts. One of the main functions of the spine is to support the whole body and the vital structures of the body, such as nerves and the spinal cord that are located inside it. The spinal cord, which is located inside the spine, is one of the main components of the central nervous system of vertebrates, which is responsible for transmitting sensory and motional messages between the brain and other parts of the body [1]. This organ is one of the most sensitive parts of the central nervous system [2], and damage to it is one of the common neurological [3] and the biggest problems related to people's health $[4,5]$. The number of people with spinal cord injury in the United States is currently estimated to be 294,000 , ranging from 250,000 to 368,000 . Evidence suggests that there are about 70,000 to 90,000 patients with spinal cord injury in Iran [4]. The age of patients with spinal cord injury has increased from 29 to 43 years from 1972 , and $78 \%$ of new cases are men [6].

Causes of spinal cord injury include injuries from accidents and motor vehicles, falling or being hit by an object, interpersonal fights, and sports injuries, which together account for $93 \%$ of the causes of spinal cord injury. Other causes, such as spinal cord injuries due to non-traumatic factors, such as spinal canal stenosis, spinal tumors, ischemia, infection, and myelitis account for about 7\% [7]. Spinal cord injuries have far-reaching physical and psychological consequences in people's lives [8], and generally affect the quality of life [9-11], and lead to severe functional limitations [12]. They can also disrupt a patient's participation in social activities as well as the patient's skills and job opportunities because they alter the routine occupational performance of individuals [13] and create challenges for those involved [14].
In general, all areas of a person's occupational performance are exposed to damage after developing spinal cord injury. Among areas of occupation that are less considered, sleep and rest can be mentioned [15]. Sleep problems and the resulting stress cause disruption and imbalance in a person's life [16]. Sleep is a reversible state that refers to varying degrees of sensory unresponsiveness and behavioral immobility [17]. Inadequate sleep is a condition, in which a person's alertness, function, and health are affected due to poor sleep or intermittent sleep [18]. Sleep is one of the most influential factors affecting emotions and feelings, which is one of the basic physiological needs of the body [19] and has a significant impact on individuals' daily functioning [20]. Sleep also affects the immune system response [21] and helps to rejuvenate the mind and physiological capacity and is necessary to accept new roles [22, 23].

Various studies have examined the prevalence of sleep disorders in patients with spinal cord injury. Sedghi et al. in 2018 studied 100 patients with spinal cord injury and showed that sleep disorders have a high prevalence $(100 \%)$ in patients with spinal cord injury [21]. Also, a study was conducted in the United States in 2017 on 180 participants with spinal cord injuries and showed that poor sleep quality is highly prevalent in this population [24].

If a person does not get enough sleep, he cannot expect good performance during the day [25]. The quality of life and activity of people during waking hours is greatly affected by the quality of sleep [21-27]. Therefore, having adequate and high-quality sleep is one of the most influential factors on the quality of life in people with spinal cord injury [28-30]. There are several factors affecting sleep quality. Previous studies have more or less examined some factors related to sleep quality; some studies have examined the effect of respiratory apnea on sleep quality [29]. The effect of mood factors and pain has also been studied on sleep quality [31]. Some studies have 
also suggested the possibility of effects of some factors, such as muscle spasms [11] and medications that need further studies [29].

Given the above issues and the importance of addressing sleep quality and the fact that few comprehensive studies have been done so far on factors affecting sleep quality in a focused study, this research was designed to better understand the predictors and controllers of sleep quality, and in a comprehensive study, review the factors related to sleep quality so that therapists working in this field can know the needs of this group of people with more awareness and provide more effective clinical services. Therefore, the aim of this study was to investigate the factors affecting sleep quality in patients with spinal cord injury.

\section{Materials and Methods}

A cross-sectional analytical study was conducted in 2019-2020. The statistical population consisted of patients with spinal cord injury referring to occupational therapy clinics in Tehran and Karaj and hospitalized patients and people referring to Kahrizak sanatorium in Alborz province. The study sample included 100 spinal cord injured patients who were randomly selected. Of these patients, 72 were men and 28 were women, with a duration of 6 months to more than 2 years from the time of their spinal cord injury, which was confirmed by a neurologist. Inclusion criteria included informed consent to participate in the study, spinal cord injury, the age of over 18 years, determining the neurological level of the injury by a specialist physician using paraclinical findings, having no disease associated with the nervous system, and no retardation and mental problems.

Exclusion criteria included a person's lack of interest to participate in the study. In order to carry out the research steps, after receiving the ethics code from the ethics committee of the Faculty of Rehabilitation of Iran University of Medical Sciences and finding the study sample, full explanations were provided to the participants about the research process. After receiving the informed consent, data were collected using the demographic information questionnaire, sleep quality questionnaire, respiratory apnea risk assessment questionnaire, and mood disorders questionnaire. The researcher helped the patients while filling in the questionnaires and answered their questions. Also, to prevent the participants from getting tired, some 10-minute breaks were considered for the participants after filling in each questionnaire.

The research tools included the Pittsburgh Sleep Quality Questionnaire consisting of 18 questions and seven subscales, involving mental sleep quality, sleep delay, sleep duration, sleep efficiency, sleep disorder, sleeping pills, and daily dysfunction [32]. This questionnaire is the most reliable tool for assessing the mental quality of sleep in the past month, which is a self-reported tool measuring sleep habits. Each question is scored from 0 to 3 , which gives a score range of 0 to 21 for seven components. Montelongo et al. obtained a sensitivity of $89.6 \%$ and a specificity of $86.5 \%$ for it [33]. The validity of this questionnaire for the Iranian population was confirmed by Farrahi et al., and the sensitivity was obtained $100 \%$ and the specificity was $93 \%$, and Cronbach's alpha was 0.89 [34].

The standard STOP-BANG questionnaire was designed to assess the risk of obstructive sleep apnea and has high sensitivity and specificity. Its sensitivity, which in comparison with polysomnography, for mild, moderate, and severe hypopnea apnea is $91.7,91.6$, and $98 \%$ and its characteristics are $0.805,0.779$, and 0.755 , respectively. The validity of this questionnaire, to determine the risk of Obstructive Sleep Apnea (OSA), has been evaluated and confirmed in epidemiological studies $[35,36]$. In this questionnaire, four questions considered snoring, fatigue, and drowsiness during the day, sleep apnea and high blood pressure with yes/no answers, and four parameters of being over 50 years of age, being a man, neck circumference more than $43 \mathrm{~cm}$ in men and more than $41 \mathrm{~cm}$ in women, Body Mass Index (BMI) greater than or equal to $35 \mathrm{~kg} / \mathrm{m}^{2}$ were obtained with a yes/no answers. Positive answers to zero to two questions show a low risk of OSA. three to four positive answers are considered an average risk of developing OSA; five to eight positive answers indicate high risk. The high-risk group also involved subjects whose number of positive responses was equal to or more than two plus being male, BMI more than $35 \mathrm{~kg}$ / $\mathrm{m}^{2}$, or neck circumference more than 43 in men and more than $41 \mathrm{~cm}$ in women [37].

Beck Anxiety Inventory (BAI) and Beck Depression Inventory (BDI) were used to collect mood data. The BIA Questionnaire was designed in 1988 by Beck et al. to measure anxiety and consisted of 21 items with four options to choose from for each item. Every expression reflects one symptom of anxiety that is usually experienced by people who are clinically anxious or who are in a state of anxiety. Psychometric properties of BAI were measured in the age and gender classes of the Iranian population. The test results had decent validity, reliability, and internal consistency with Cronbach's alpha of 0.92 [38]. BDI was published in 1987 by Beck et al. The test consists of a total of 21 items related to different symptoms that subjects must answer on a 4-point scale 
from zero to 3. Cronbach's alpha of this questionnaire is estimated to be 0.91 ; the split-half correlation coefficient is 0.89 ; the two-week retest coefficient is 0.94 , and the correlation coefficient with the first edition is estimated to be 0.93 [39]. Data were analyzed using SPSS v. 22 software and statistical, descriptive, and inferential tests.

\section{Results}

Most of the subjects were male (72\%) and ranged in age from 30 to 40 . Also, 70\% were living at home with their families and $64 \%$ of them were unemployed.

Table 1 shows that $72 \%$ of the participants were male and $28 \%$ were female. Also, $32 \%$ had injuries in the cervical region, $58 \%$ in the thoracic region, and $10 \%$ in the lumbar region. The chart below shows the time elapsed after injury in the participants, indicating that the period elapsed after injury in $78 \%$ of participants was more than 2

Table 1. Demographic information of participants

\begin{tabular}{|c|c|c|}
\hline & & No. (\%)* \\
\hline \multirow{3}{*}{ Gender } & Male & $72(72.0)$ \\
\hline & & \\
\hline & Female & $28(28.0)$ \\
\hline \multirow{5}{*}{ Age } & $18-20$ years & $7(7.0)$ \\
\hline & 20-30 years & $42(42.0)$ \\
\hline & & \\
\hline & $30-40$ years & $31(31.0)$ \\
\hline & $40-50$ years & $20(20.0)$ \\
\hline \multirow{3}{*}{ Level of lesion } & Cervical & $32(32.0)$ \\
\hline & Thoracic & $58(58.0)$ \\
\hline & Lumbar & $10(10.0)$ \\
\hline \multirow{2}{*}{ Place of living } & Home & $70(70.0)$ \\
\hline & Capotorium & $30 / 3001$ \\
\hline \multirow{9}{*}{ Medications } & Not taking medication & $33(33.0)$ \\
\hline & Hypertension & $8(8.0)$ \\
\hline & Analgesic & $4(4.0)$ \\
\hline & Anti-spasm & $24(24.0)$ \\
\hline & & \\
\hline & Anti-spasm and anti-hypertension & $4(4.0)$ \\
\hline & Anti-spasm and pain-killer & $18(18.0)$ \\
\hline & Pain-killer and anti-hypertension & $7(7.0)$ \\
\hline & All three types & $2(2.0)$ \\
\hline \multirow[b]{2}{*}{ Job status } & Employed & $36(36.0)$ \\
\hline & Unemployed & $64(64.0)$ \\
\hline \multirow[b]{2}{*}{ Injury status } & Major & $82(82.0)$ \\
\hline & Minor & $18(18.0)$ \\
\hline
\end{tabular}

*Given that the sample size was 100 , the absolute and relative frequencies are the same. 


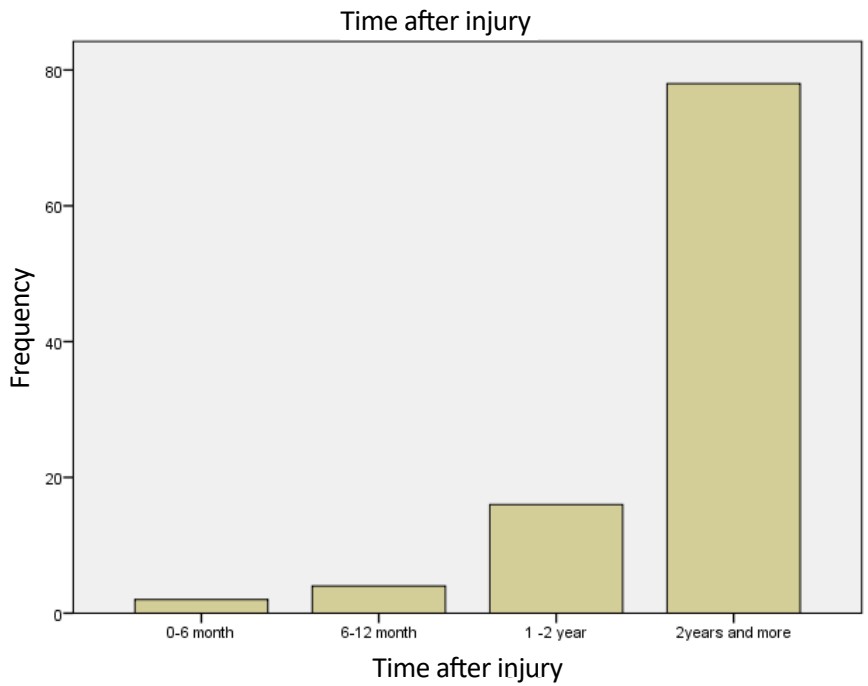

Figure 1. Bar chart showing the time elapsed after injury in participants

years, $16 \%$ reported 1 to 2 years, $4 \%$ of cases reported 6 to 12 months, and $2 \%$ reported less than 6 months (Figure 1).

Table 2 reveals that there was a significant relationship between mood disorders (anxiety and depression), the likelihood of respiratory apnea, pain and Activities of Daily Living (ADL) score, and sleep quality. The negative correlation coefficient of the ADL indicates that the higher the level of independence in the individual, the better the quality of sleep (i.e., the lower the PSQI test score) and in Table 3 shows the mean and standard deviation of sleep quality scores and its components in patients with spinal cord injury. Table 4 indicates no significant relationship observed between sleep and muscle tone. Table 5 indicates that there was a significant relationship between functional mobility and sleep quality.

\section{Discussion}

The aim of this study was to evaluate the factors affecting sleep quality in patients with spinal cord injury. According to the results, sleep quality was poor in $66 \%$ of participants, which means that $66 \%$ of participants in the Pittsburgh questionnaire reported a score higher than 5, which is consistent with the study by Sedghi et al. [21]. It is also in line with other studies on sleep quality in patients with systolic heart disease, chemical warfare victims, patients with spinal cord injury, and patients with stroke. In addition, the results showed that the overall quality of sleep in women is lower than in men (Pittsburgh questionnaire's score is higher in the female population). This difference can be due to the higher level of activity of men during the day than women. The results also showed that the quality of sleep in patients living in sanatoriums and care centers is lower than people living in their own homes. This can be due to the factors, such as being in the same room with other patients or the noises that are made during the night by the staff of the center or other patients. Also, the quality of sleep in the group of patients with spinal cord injuries was lower than the other two groups. This can be due to more sensory and motor limitations of these people, which causes poor quality and interrupted sleep in them.

Table 2. Correlation between sleep quality and pain, probability of apnea, depression, anxiety

\begin{tabular}{cccc}
\hline Dependent Variable & Independent Variable & The Correlation Coefficient & Significance Level \\
\hline & Beck score & 0.565 & $\leq 0.001$ \\
STOP BANG & 0.505 & $\leq 0.001$ \\
Sleep quality & Beck Anxiety & 0.413 & $\leq 0.001$ \\
& Barthel & -0.471 & $\leq 0.001$ \\
& Analog pain & 0.316 & $\leq 0.01$ \\
\hline
\end{tabular}


Table 3. Mean and standard deviation of sleep quality scores and its components in patients with spinal cord injury ( $\mathrm{n}=100$ )

\begin{tabular}{|c|c|}
\hline Variables & Mean士SD \\
\hline Mental quality of sleep & $1.87 \pm 2.99$ \\
\hline Delay in falling asleep & $1.29 \pm 0.92$ \\
\hline Duration of sleep & $1.23 \pm 1.03$ \\
\hline Sleep efficiency & $1.06 \pm 0.88$ \\
\hline Sleep disorders & $1.40 \pm 0.88$ \\
\hline Taking sleeping pills & $0.45 \pm 0.89$ \\
\hline Dysfunction in daily affairs & $0.82 \pm 0.82$ \\
\hline Total score of sleep quality & $8.15 \pm 4.42$ \\
\hline Possibility of respiratory apnea & $3.93 \pm 2.26$ \\
\hline Depression score & $20.21 \pm 11.09$ \\
\hline Anxiety score & $15.36 \pm 13.40$ \\
\hline The level of pain & $4.32 \pm 2.99$ \\
\hline Barthel Score (Activities of Daily Living (ADL)) & $52.06 \pm 23.77$ \\
\hline
\end{tabular}

Table 4. Evaluation of the relationship between muscle tone and sleep quality in patients

\begin{tabular}{ccc}
\hline & & Sleep Quality \\
\cline { 2 - 3 } Tone & Kendall's Tau_b & Significance \\
\hline Upper limb muscle tone & 64.903 & $\geq 0.01$ \\
Lower limb muscle tone & -0.93 & $\geq 0.01$ \\
\hline
\end{tabular}

There was also a significant relationship between physiological factors, such as the likelihood of respiratory apnea, pain, and muscle tone, and sleep quality $(\mathrm{P} \leq 0.01)$, i.e. the higher the risk of respiratory apnea, pain, and muscle tone, the higher the PSQI score, which means the low quality (the higher the PSQI score, the lower the quality of sleep). These results are consistent with a study in Chicago carried out in 2016 [40]. Also, a study conducted in 2021 by Allesio Conti entitled "The relationship between sleep quality and participation in people with spinal cord injury" showed that sleep quality is poor in these people [41].

The results also showed a significant relationship between emotional factors, i.e. anxiety and depression scores, and the quality of sleep $(\mathrm{P}<0.001)$; this means that the more a person suffers from emotional disorders, the lower is his quality of sleep. our results are in line with those reported by January et al [26]. Also, in another study conducted by Aydin Tugba et al. in 2020,

Table 5. Investigating the relationship between functional mobility and sleep quality

\begin{tabular}{ccc}
\hline Component if Function & \multicolumn{2}{c}{ Sleep Quality } \\
\cline { 2 - 3 } & Kendall's Tau_b & Significance \\
\hline Functional mobility & 0.302 & $\leq 0.001$ \\
\hline
\end{tabular}


the quality of sleep in spinal cord injury patients was assessed using the PSQI tool. They reported a significant relationship between sleep quality and mood changes, such as associative depression [42].

There was a significant relationship between ADL, which indicates the degree of independence in daily life activities, and sleep quality score $(\mathrm{P} \leq 0.001)$. Considering the negative coefficient of correlation, the higher a person has functional independence, the lower is the PSQI score, resulting in a higher quality of sleep, which indicates its importance in people's lives. There was also no significant relationship between muscle tone and sleep quality $(\mathrm{P} \geq 0.05)$. This means that muscle spasm and tone had no effect on participants' sleep quality, which was not consistent with a study by Andresen et al. in 2016 [11]. There was also a significant relationship between functional mobility and sleep quality $(\mathrm{P} \leq 0.05)$, indicating the effect of the type of means of mobility on the quality of sleep.

\section{Conclusion}

The quality of sleep in patients with spinal cord injury is low and is significantly associated with factors, such as the likelihood of respiratory apnea, pain, mood factors of anxiety and depression, muscle tone, functional mobility, and the degree of independence in daily activities.

\section{Ethical Considerations}

\section{Compliance with ethical guidelines}

This study was approved by the Ethics Committee of Iran University of Medical Sciences (IR.IUMS. REC.1398.1356). The participants signed an informed consent form after being informed of the privacy policy as well as the purpose, importance, methods, and risks associated with this study.

Funding

This study was supported by the Iran Universality of Medical Sciences.

\section{Authors' contributions}

All authors equally contributed to preparing this article.

\section{Conflict of interest}

The authors declared no conflict of interest.

\section{Acknowledgments}

We appreciate all participants in this study.

\section{References}

[1] Kreinest M, Rillig J, Grützner PA, Küffer M, Tinelli M, Matschke $\mathrm{S}$. Analysis of complications and perioperative data after open or percutaneous dorsal instrumentation following traumatic spinal fracture of the thoracic and lumbar spine: A retrospective cohort study including 491 patients. Eur Spine J. 2017; 26(5):1535-40. [DOI:10.1007/s00586-016-4911-8] [PMID]

[2] Chen HY, Boore JR. Establishing a super-link system: Spinal cord injury rehabilitation nursing. J Adv Nurs. 2007; 57(6):639-48. [DOI:10.1111/j.1365-2648.2006.04160.x] [PMID]

[3] Badhiwala JH, Wilson JR, Fehlings MG. Global burden of traumatic brain and spinal cord injury. Lancet Neurol. 2019; 18(1):24-5. [DOI:10.1016/S1474-4422(18)30444-7]

[4] Babamohamadi H, Negarandeh R, Dehghan-Nayeri N. Barriers to and facilitators of coping with spinal cord injury for Iranian patients: A qualitative study. Nurs Health Sci. 2011; 13(2):207-15. [DOI:10.1111/j.1442-2018.2011.00602.x] [PMID]

[5] Abdolahi M. [The assessment of rate of utilizing rehabilitation services among spinal cord injured cases of Bam earthquake (Persian)]. J Qual Res Health Sci. 2011; 010(1):1-6. http://jqr1.kmu.ac.ir/article_90702.html

[6] No Author. Spinal Cord Injury Facts and Figures at a Glance. J Spinal Cord Med. 2013; 35(4):197-8. https://doi.org/10.1179/1079026 812Z.00000000063

[7] New PW, Lee BB, Cripps R, Vogel LC, Scheinberg A, Waugh MC. Global mapping for the epidemiology of paediatric spinal cord damage: Towards a living data repository. Spinal Cord. 2019; 57(3):183. [DOI:10.1038/s41393-018-0209-5] [PMID]

[8] Ma JK, West CR, Martin Ginis KA. The effects of a patient and provider co-developed, behavioral physical activity intervention on physical activity, psychosocial predictors, and fitness in individuals with spinal cord injury: A randomized controlled trial. Sports Med. 2019; 49(7):1117-31. [DOI:10.1007/s40279-019-01118-5] [PMID]

[9] Foongchomcheay A, Eitivipart AC, Kespichayawattana J, Muangngoen M. Quality of life after spinal cord injury in Thai individuals: A mixed-methods study. Hong Kong Physiother J. 2019; 39(1):35-55. [DOI:10.1142/S1013702519500045] [PMID] [PMCID]

[10] Rivers CS, Fallah N, Noonan VK, Whitehurst DG, Schwartz $\mathrm{CE}$, Finkelstein JA, et al. Health conditions: Effect on function, health-related quality of life, and life satisfaction after traumatic spinal cord injury. A prospective observational registry cohort study. Arch Phys Med Rehabil. 2018; 99(3):443-51. [DOI:10.1016/j. apmr.2017.06.012] [PMID]

[11] Andresen SR, Biering-Sørensen F, Hagen EM, Nielsen JF, Bach FW, Finnerup NB. Pain, spasticity and quality of life in individuals with traumatic spinal cord injury in Denmark. Spinal Cord. 2016; 54(11):973-9. [DOI:10.1038/sc.2016.46] [PMID]

[12] Richard-Denis A, Thompson C, Mac-Thiong JM. Quality of life in the subacute period following a cervical traumatic spinal cord in- 
jury based on the initial severity of the injury: A prospective cohor study. Spinal Cord. 2018; 56(11):1042-50. [DOI:10.1038/s41393018-0178-8] [PMID]

[13] Nas K, Yazmalar L, Șah V, Aydın A, Öneș K. Rehabilitation of spinal cord injuries. World J Orthop. 2015; 6(1):8-16. [DOI:10.5312/ wjo.v6.i1.8] [PMID] [PMCID]

[14] Craig A, Guest R, Tran Y, Middleton J. Cognitive impairment and mood states after spinal cord injury. J Neurotrauma. 2017; 34(6):1156-63. [DOI:10.1089/neu.2016.4632] [PMID]

[15] Chiodo AE, Sitrin RG, Bauman KA. Sleep disordered breathing in spinal cord injury: A systematic review. J Spinal Cord Med. 2016; 39(4):374-82. [DOI:10.1080/10790268.2015.1126449] [PMID] [PMCID]

[16] McCombie RP, Wolfe R. Sleep as an occupation: Perceptions and assessment behaviors of practicing occupational therapists. Am J Occup Ther. 2017; 71(4_Supplement_1):7111510172p1. [DOI:10.5014/ajot.2017.71S1-PO1123]

[17] Alfonsi V, D'Atri A, Scarpelli S, Mangiaruga A, De Gennaro L. Sleep talking: A viable access to mental processes during sleep. Sleep Med Rev. 2019; 44:12-22. [DOI:10.1016/j.smrv.2018.12.001] [PMID]

[18] Cirelli C, Benca R, Eichler AF. Insufficient sleep: Definition, epidemiology, and adverse outcomes [Internet]. 2021 [Updated 2021 Jun]. Available from: https://www.uptodate.com/contents/insufficient-sleep-definition-epidemiology-and-adverse-outcomes/print

[19] Owens JA; Weiss MR. Insufficient sleep in adolescents: Causes and consequences. Minerva Pediatr. 2017; 69(4):326-36. [DOI:10.1016/j.sleh.2017.11.006]

[20] Lallukka T, Sivertsen B, Kronholm E, Bin YS, Øverland S, Glozier N. Association of sleep duration and sleep quality with the physical, social, and emotional functioning among Australian adults. Sleep Health. 2018; 4(2):194-200. [DOI:10.1016/j.sleh.2017.11.006] [PMID]

[21] Sedghi N, Monjamed Z, Mousavi A, Ghorbani S. [Sleep quality in patients with spinal cord injury Khatamolanbia Hospital (Persian)] Iran J War Public Health. 2015; 7(3):127-32. http://ijwph.ir/article1-488-en.html

[22] Haponik EF, Smith PL, Bohlman ME, Allen RP, Goldman SM, Bleecker ER. Computerized tomography in obstructive sleep apnea. Correlation of airway size with physiology during sleep and wakefulness. Am Rev Respir Dis. 1983; 127(2):221-6. [PMID]

[23] Carley DW, Farabi SS. Physiology of sleep. Diabetes Spectr. 2016; 29(1):5-9. [DOI:10.2337/diaspect.29.1.5] [PMID] [PMCID]

[24] January AM, Zebracki K, Chlan KM, Vogel LC. Sleep, well-being and psychological symptoms in adults with pediatric-onset spinal cord injury. Rehabil Psychol. 2015; 60(4):328-34. [DOI:10.1037] rep0000061] [PMID]

[25] Murray JM, Phillips AJK, Magee M, Sletten TL, Gordon C, Lovato $\mathrm{N}$, et al. Sleep regularity is associated with sleep-wake and circadian timing, and mediates daytime function in delayed sleepwake phase disorder. Sleep Med. 2019; 58:93-101. [DOI:10.1016/j. sleep.2019.03.009] [PMID]

[26] January AM, Zebracki K, Chlan KM, Vogel LC. Poor sleep in adults with pediatric-onset spinal cord injury: Associations with pain, health, and activity. J Spinal Cord Med. 2017; 40(5):560-6. [D OI:10.1080/10790268.2017.1308109] [PMID] [PMCID]
[27] Chasens ER, Luyster FS. Effect of sleep disturbances on quality of life, diabetes self-care behavior, and patient-reported outcomes Diabetes Spectr. 2016; 29(1):20-3. [DOI:10.2337/diaspect.29.1.20] [PMID] [PMCID]

[28] Sakakibara BM, Miller WC, Orenczuk SG, Wolfe DL; SCIRE Research Team. A systematic review of depression and anxiety measures used with individuals with spinal cord injury. Spinal Cord. 2009; 47(12):841-51. [DOI:10.1038/sc.2009.93] [PMID] [PMCID]

[29] Hultén VD, Biering-Sørensen F, Jørgensen NR, Jennum PJ. A review of sleep research in patients with spinal cord injury. J Spinal Cord Med. 2018; 43(6): 775-96. [DOI:10.1038/sc.2009.93]

[30] Fogelberg DJ, Leland NE, Blanchard J, Rich TJ, Clark FA. Qualitative experience of sleep in individuals with spinal cord injury. OTJR (Thorofare N J). 2017; 37(2):89-97. [DOI:10.1177/1539449217691978] [PMID] [PMCID]

[31] Burke D, Fullen BM, Stokes D, Lennon O. Neuropathic pain prevalence following spinal cord injury: A systematic review and metaanalysis. Eur J Pain. 2017; 21(1):29-44. [DOI:10.1002/ejp.905] [PMID]

[32] Matin M, Taheri Otaghsara SM, Latifi S, Javidan AN, Koushk $\mathrm{D}$, Abedi F. Subjective sleep quality in Iranian patients with spinal cord injury: Results of pittsburgh sleep quality index in a referral center. J Neurol Psychol. 2014; 2(1):4. https://www.researchgate net/profile/Sahar-Latifi/publication/262495851_Subjective_Sleep_ Quality in Iranian Patients with Spinal Cord Injury Results_of_Pittsburgh_Sleep_Quality_Index_in_a_Referral_Center/ links/00b7d539d42b5e7f40000000/Subjective-Sleep-Quality-inIranian-Patients-with-Spinal-Cord-Injury-Results-of-PittsburghSleep-Quality-Index-in-a-Referral-Center.pdf

[33] Montelongo-Rodríguez K, Almendra-Pegueros R, ValenciaSánchez L, De Leon-Diaz de Leon E, García-Díaz A, Esmer-Sánchez D, et al. DPP-4 levels are increased in subjects with poor sleep quality. Metab Syndr Relat Disord. 2019; 17(8):411-5. [DOI:10.1089/ met.2019.0003] [PMID]

[34] Farrahi Moghaddam J, Nakhaee N, Sheibani V, Garrusi B, Amirkafi A. Reliability and validity of the Persian version of the Pittsburgh Sleep Quality Index (PSQI-P). Sleep Breath. 2012; 16(1):79-82. [DOI:10.1007/s11325-010-0478-5] [PMID]

[35] Sadeghniiat-Haghighi K, Montazeri A, Khajeh-Mehrizi A, Ghajarzadeh M, Alemohammad ZB, Aminian O, et al. The STOPBANG Questionnaire: Reliability and validity of the Persian version in sleep clinic population. Qual Life Res. 2015; 24(8):2025-30. [DOI:10.1007/s11136-015-0923-9] [PMID]

[36] Nagappa M, Liao P, Wong J, Auckley D, Ramachandran SK, Memtsoudis S, et al. Validation of the STOP-Bang Questionnaire as a screening tool for obstructive sleep apnea among different populations: A systematic review and meta-analysis. PLoS One. 2015; 10(12):e0143697. [DOI:10.1371/journal.pone.0143697] [PMID] [PMCID]

[37] Chung F, Yang Y, Brown R, Liao P. Alternative scoring models of STOP-bang questionnaire improve specificity to detect undiagnosed obstructive sleep apnea. J Clin Sleep Med. 2014; 10(9):951-8 [DOI:10.5664/jcsm.4022] [PMID] [PMCID]

[38] Hossein Kaviani H, Mousavi A S. [Psychometric properties of the Persian version of Beck Anxiety Inventory (BAI) (Persian)]. Tehran Univ Med J. 2008; 66(2):136-40. http://tumj.tums.ac.ir/article1-641-en.html

[39] Ebrahimi A, Barekatain M, Bornamanesh A, Nassiri H. [Psychometric properties of the Persian Version of Bipolar Depression Rat- 
ing Scale (BDRS) in patients and general population (Persian)]. Iran J Psychiatr Clin Psychol. 2015; 21(1):60-8. http://ijpcp.iums.ac.ir/ article-1-2355-en.html

[40] McCormick ZL, Chu SK, Binler D, Neudorf D, Mathur SN, Lee J, et al. Intrathecal versus oral baclofen: A matched cohort study of spasticity, pain, sleep, fatigue, and quality of life. PM R. 2016; 8(6):553-62. [DOI:10.1016/j.pmrj.2015.10.005] [PMID]

[41] Conti A, Sperlinga R, Luciani M, Crenna MF, Piovan C, Scavino $\mathrm{E}$, et al. Association between sleep quality and participation in people with spinal cord injury: A preliminary study. J Spinal Cord Med. 2021; 1-8. [DOI:10.1080/10790268.2021.1876818] [PMID]

[42] Aydin T, Öneş K, Kesiktaş FN, Corum M, Kalaoğlu E, Karacan I. Sleep quality in individuals with short-duration chronic spinal cord injury. Int J Rehabil Res. 2020; 43(4):369-75. [DOI:10.1097/ MRR.0000000000000436] [PMID] 


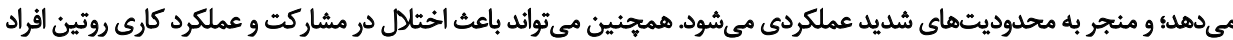

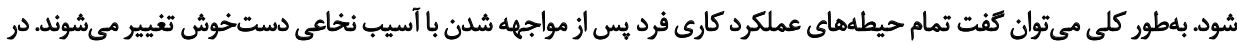

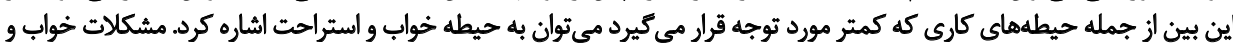

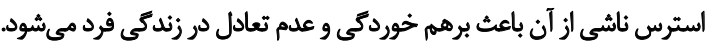

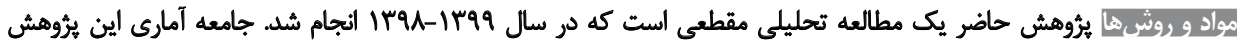

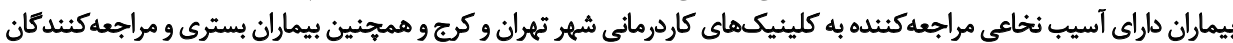

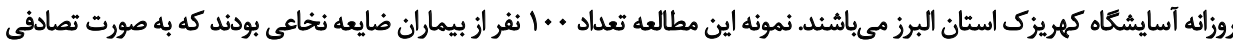

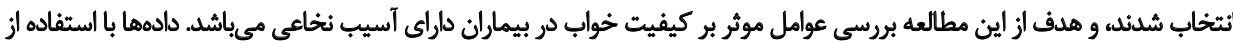

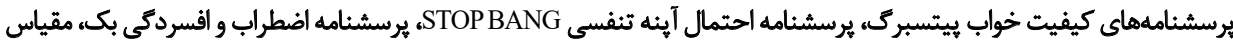

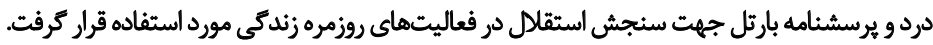

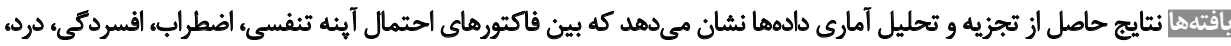

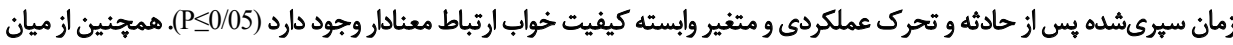

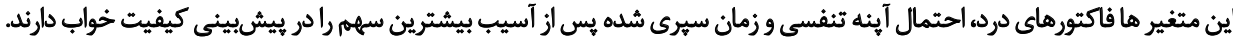

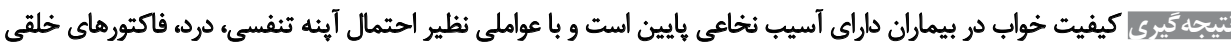

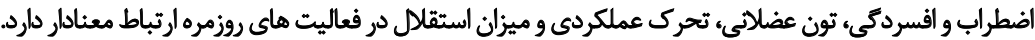

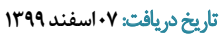

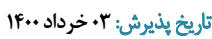

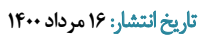

